\title{
THE EFFECT OF WOM COMMUNICATION WITH CLOSE OTHERS ON REPEAT PURCHASE
}

\author{
Kaichi Saito, Meiji Gakuin University, Japan
}

\begin{abstract}
Consumers often talk about consumer packaged goods (CPG) brands with their family and friends. One notable feature of word-of-mouth (WOM) communication is that a brand that has been purchased by all participants in the conversation often becomes a topic. For example, consumers who have purchased Red Bull often talk about the brand among themselves. Previous studies have actively examined the effect of WOM on the first purchase of a new brand (i.e., a brand that has not been purchased) in the categories of books (Chevalier and Mayzlin 2006), movies (Liu 2006), and games (Zhu and Zhang 2010). However, how WOM influences repeat purchases of a CPG brand has remained virtually unexplored, although some studies imply that consumer interactions promote repeat purchases (e.g., Baghurst, Record, and Leppard 2000).

This study examines the effect of WOM on a consideration of a brand that has been purchased, as well as of a brand never purchased before, since recent studies show that WOM has a greater impact on consideration set composition than on choice from the consideration set (e.g., Jang, Prasad, and Ratchford 2012). The present study considers consumer heterogeneity in consideration set formation and explores how the responses to the WOM are moderated by consumer characteristics.
\end{abstract}

I hypothesize that consumers are more likely to consider a brand that he/she has purchased when the brand becomes a topic of conversation with close others, for the following two reasons. First, brands can function as a means of bringing the consumer closer to family and friends (e.g., Bearden, Netemeyer, and Teel 1989). When talking about a given brand with the family and friends, the consumer realizes that his/her family and friends have purchased the same brand and are interested in that brand. This information allows the consumer to understand that, by purchasing and talking about the brand repeatedly, he/she can build a closer relationship with family and friends. By recognizing such a social function of the brand, the consumer is more likely to consider the brand. Another reason is that WOM communication with close others on a purchased brand makes the brand more accessible in the consumer's memory (cf. Berger and Schwartz 2011). The more accessible the brand is in memory, the more likely the brand will be considered (Bronnenberg and Vanhonecker 1996; Nedungadi 1990).

An empirical analysis was conducted using the survey data provided by Yomiuri Advertising Company. In this survey, respondents were presented with 15 brands of beer and asked questions about consideration, purchase experience, and WOM from close others of each brand, as well as several consumer characteristics. The data contained 9326 consideration observations from 863 respondents. Approximately 60\% (1.24/2.1) of WOM received were on previously purchased brands. The data was fitted to a hierarchical Bayesian binomial logit model (Allenby and Ginter 1995). In this model, the response parameter vector of consumer $h$ is formulated as: $\boldsymbol{\beta}_{h} \sim N\left(\Gamma \mathbf{z}_{h}, \mathbf{V}_{\beta}\right)$, where $\mathbf{z}_{h}$ is a characteristic vector of consumer $h$, includes the intercept and consumer characteristics. The coefficients of the consumer characteristics in $\Gamma$ capture the moderating effects of the consumer characteristics, whereas the intercepts capture the effects of explanatory variables not dependent on the characteristics. $\mathbf{V}_{\beta}$ captures unobserved heterogeneity. Parameters are estimated by using MCMC.

The estimate of intercept of WOM about a previously purchased brand was significant and its sign was positive $(\gamma=2.42)$, as expected. The estimated moderating effects of consumer characteristics reveal that the response to WOM about a brand previously purchased is moderated by the tendency of conformity in brand choice $(\gamma=.96)$. One inducement of conforming purchase behavior is the intent to build a closer relationship with one's family and friends by purchasing/using the same brand and talking about the consumption experience of the brand. Thus, consumers who tend to choose the same brand as many other people purchase more sensitively respond to WOM about a purchased brand. The results also show that, consistent with previous research, WOM about a brand never purchased has a positive impact on the brand consideration $(\gamma=$ $2.33)$ and the effect of WOM on a brand never purchased is moderated by the importance of experience attribute $(\gamma=.33)$.

This study contributes to WOM research by showing that (1) WOM promotes the consideration even of a purchased brand and (2) the influence of WOM on the consideration of brands previously purchased and brands never purchased are moderated by different consumer characteristics. One limitation of this study is that the empirical analysis was conducted using only the data on beer. The empirical results should be validated using data on other categories.

References available upon request 